\title{
STRUCTURAL TRANSFORMATIONS OF PIRIFORM NEURONS IN DIFFERENT AREAS OF THE HUMAN CEREBELLAR CORTEX FROM BIRTH TO 6 YEARS
}

\section{Tatiana Tsekhmistrenko ${ }^{1,2}$, Vadim Astashov $^{1}(\mathbb{0}$, Valentin Kozlov', Aslan Mazloev' ${ }^{1}$}

\author{
${ }^{1}$ Peoples Friendship University of Russia (RUDN University), Moscow \\ ${ }^{2}$ Institute of Developmental Physiology, Russian Academy of Education, \\ Moscow, Russia
}

\section{tsekhmistrenko_ta@pfur.ru}

of the posterior lobe of cerebellum, which is related to bimanual coordination control [2], planning, and preparation of arbitrary movements [1]. In addition, the structural and functional features of $\mathrm{H} \mathrm{VI}$ and H.VII B lobules are currently being actively studied in connection with data on their activation in performing cognitive tasks and implementing a wide range of non-motor functions [11].

\section{OB JEC T IVE}

The aim of this work was to study age-related changes and interhemispheric asymmetry of piriform neurons (Purkinje cells) in functionally different areas of cerebellar cortex in children.

\section{MATERIALS AND METHODS}

A total of 36 male cerebellums of people aged from birth to 6 years who died from injuries unrelated to brain damage were studied. Collection of sectional material was authorized by the Ethical Commission of the Institute of Developmental Physiology of the Russian Academy of Education (Protocol No. 3 of 23.05.1996) and was carried out in the forensic mortuaries of Moscow and Moscow region. The material was grouped in annual intervals. Pieces of cerebellar cortex were taken for histological research from the posterior part of anterior quadrangular lobule $(\mathrm{H} \mathrm{V})$, posterior quadrangular lobule $(\mathrm{H} \mathrm{VI})$ and paramedian lobule (H VII B), recorded in 10\% neutral formalin, dehydrated in ascending alcohols and poured into paraffin. On sagittal slices of 10 microns thick, painted with cresyl violet (Nissl's staining), by computer morphometry using Image Tools technology (National Institutes of Health, USA) and the ImageExpert ${ }^{\text {m }}$ Gauge (NEXSYS, Russia) geometric measurement programs measured the area of piriform neurons' profile fields (APN) in the histological cut plane at the apex and lateral wall of the folium of cerebellum. The sample size for each section was not less than 10, for each histological preparation - not less than 40, for each age - not less than 120 measurements. For indicators of different age groups, the mean value, the error of the mean and confidence intervals [9] with the level of significance $\mathrm{P}=95 \%$ $(\mathrm{p}<0.05)$ were calculated. 


\section{RESULTS}

In newborns, APN was $63.8 \pm 2.2 \mu \mathrm{m}^{2}$ in the anterior quadrangular lobule on the right (H VR) on average, and $40.1 \pm 0.7 \mu \mathrm{m}^{2}$ in the same lobule on the left (H.VL). By the time of birth, significant differences in the individual mean group sizes of piriform neurons in the anterior lobe of the cerebellum on our material were observed in $75 \%$ of cases. At the same time, the size of piriform neurons on the right was 1.5-1.7 times larger on average than on the left. APN in the anterior quadrangular lobule of both right and left increased by the end of the first year of life, by 2 and 5 years (Fig. 1). In the H VR area, the size of piriform neurons was 1.8 times larger at 1 year, 2.1 times larger at 2 years and 3.0 times larger at 5 years compared to newborns. The growth rate of piriform neurons in the H VL area from birth to 6 years was higher than that of H VR. In the $\mathrm{H}$ VL region, the area of piriform neurons on the slice was 3.5 times larger et 1 year, 4.0 times larger at 2 years and 4.6 times larger at 5 years compared to newborns. Right-sided APN asymmetry, which was observed in the anterior lobe of neonatal cerebellum, was replaced by marked left-sided asymmetry in children aged 1-2 years. At this age range, the piriform neurons on the left were 1.2 larger than on the right. After 2 years, no asymmetry was observed in the anterior quadrangular lobule of piriform neurons in terms of both mean group and individual dimensional parameters. By the age of 6 years, the area of piriform neurons in the anterior quadrangular lobule of the cerebellum was $182.2 \pm 6.1 \mu \mathrm{m}^{2}$ on the average on the right, and $175.3 \pm 4.7 \mu \mathrm{m}^{2}$ on the left.

In the posterior quadrangular lobule of newborns, APN was $59.8 \pm 0.5 \mu \mathrm{m}^{2}$ on the average right (H VIR) and $39.8 \pm 1.0 \mu \mathrm{m}^{2}$ on the left (H VIL).As in the anterior cerebellar lobe, $75 \%$ of newborns had piriform neurons in the posterior quadrangular lobule of the right cerebellar hemisphere, on average, 1.5 times larger than in the left hemisphere. The area of piriform neurons in the posterior quadrangular lobule on the right increased to 1,2 and 6 years, and on the left - to 1, 2 and 5 years (Fig. 2). In the area of H VIR, the size of piriform neurons was 1.9 times larger at 1 year, 2.6 times larger at 2 years and 3.1 times larger at 6 years compared to newborns. In the region of H VIL, the area of piriform neurons was 3.4 times larger by 1 year, 4.0 times larger by 2 years and 4.6 times larger by 5 years than that of newborns. During the first and fifth years of life, left-sided asymmetry of mean group and individual piriform neuronal dimensions in the posterior quadrangular lobule was observed: APN on the left was 1.2 times greater than on the right. By 6 years of age, no interhemispheric differences in the dimensions of piriform neurons in the posterior quad- rangular lobule were observed. APN was on average $185.4 \pm 5.4 \mu^{2}$ in the H VIR region and $186.1 \pm 4.6 \mu \mathrm{m}^{2}$ in H VIL.

In the paramedian lobule in newborns, APN was $41.3 \pm 1.5 \mu \mathrm{m}^{2}$ on the right side average (H VII BR) and $40.5 \pm 0.9 \mathrm{~mm}^{2}$ on the left side (H VII BL). APN in the paramedian lobule on the right increased to 1, 2 and 6 years, on the left to 1, 2, 3 and 6 years (Fig. 3). In the $\mathrm{H}$ VII BR region, piriform neurons were 2.7 times larger than newborns by 1 year, 3.3 times larger than newborns by 2 years and 4.6 times larger than newborns by 6 years. In the H VII BL region, APN was 3.1 times bigger by the end of 1 year, 3.9 times bigger by the end of 2 years, 4.3 times bigger by the end of 3 years, and 4.6 times bigger by the end of 6 years compared to newborns. At the age of 2 to 4 years in the paramedian lobule cortex, the piriform neurons on the left were 1.2 larger than on the right. After 4 years, no asymmetry was observed in the paramedian lobule of piriform neurons in terms of both mean group and individual dimensional parameters. By 6 years of age, APN in the paramedian lobule cortex of children was $189.9 \pm 3.9 \mu \mathrm{m}^{2}$ on the average on the right and $188.1 \pm 4.2 \mu \mathrm{m}^{2}$ on the left.

\section{DISCUSSION}

The conducted research allowed to establish that during postnatal ontogenesis intensive growth of piriform neurons in the cerebellar cortex of children is observed in the period from birth to $2-3$ years, as well as in the anterior lobe of the cerebellum to 5 years, in the posterior lobe - mainly to 6 years. Newborns have lateral right-sided asymmetry in the middle group and individual dimensional parameters of piriform neurons in the anterior and posterior quadrangular lobules of the cerebellum. Later, left-handed APN asymmetry is observed in children aged $1-5$ years, including in the anterior quadrangular lobule - during the 1 st and $2^{\text {nd }}$ years of life, in the posterior quadrangular lobule - during the 1 st and 5 th years of life, in the paramedian lobule - during the period from 2 to 4 years. It is interesting that the data on left-hand asymmetry of morphometric parameters of piriform neurons in $\mathrm{H} \mathrm{VI}$ are consistent with the data on the functional dominance of this lobule in both men and women obtained during the study of neural networks with the participation of the cerebellum [8]. In our opinion, the interhemispheric asymmetry of piriform neuronal parameters of the cerebellum is a consequence of uneven rates of their development. The heterochronic and heterodynamic character of growth and development of effector neurons of the cerebellar cortex is to a certain extent genetically programmed, and is also conditioned by a complex of direct and indirect interactions with other nerve centers, primarily with the 
HV

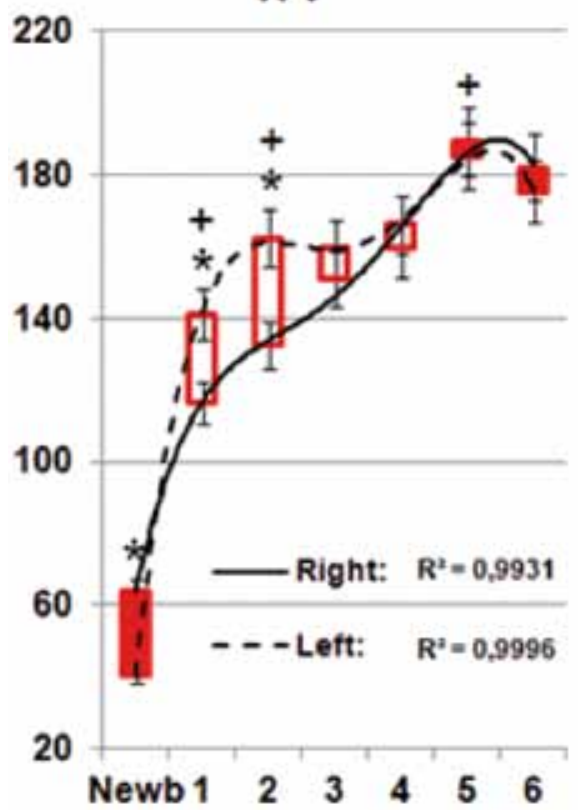

Fig. 1. Changes in the area of piriform neurons in the posterior part of anterior quadrangular lobule (HV) of the cerebellum in children from birth to 6 years of age

Here and on Fig. 2 and 3: on the $x$-axis - age in years, newb - newborns; on the y-axis - piriform neuron area in $\mu m^{2}$. The lines of approximation of average values are presented: right — right hemisphere, left — left hemisphere. $R^{2}$ indicates the level of significance of approximation. Light bars - increase of parameters on the left, dark bars - on the right. The vertical segments represent the error of the mean. ${ }^{*}$ - significant interhemispheric differences, + — significant difference from the previous significant age indicator.

cortex of large hemispheres, reticular nuclei of pons, basal nuclei, and subtalamic nuclei $[3,4,6,7]$. The data we have obtained also suggest that ascending ontogenesis increases the role of $\mathrm{H} \mathrm{VI}$ and $\mathrm{H}$ VII B cerebellar lobules in functional neural networks associated with cognitive activity and emotional control when planning complex motor tasks and behavior in general.

\section{CONCLUSION}

The results of the study suggest that postnatal growth of piriform neurons is heterochronous in functionally different areas of the cerebellar cortex. The analysis of the revealed age dynamics of dimensional parameters also allows to assume that at the early stages of postnatal development the growth and differentiation of piriform neurons in the left hemispheric lateral areas of lobules H.V, H VI and H VII B of the cerebellar cortex has a leading character in comparison with their counterlateral right hemispheric zones.
H VI

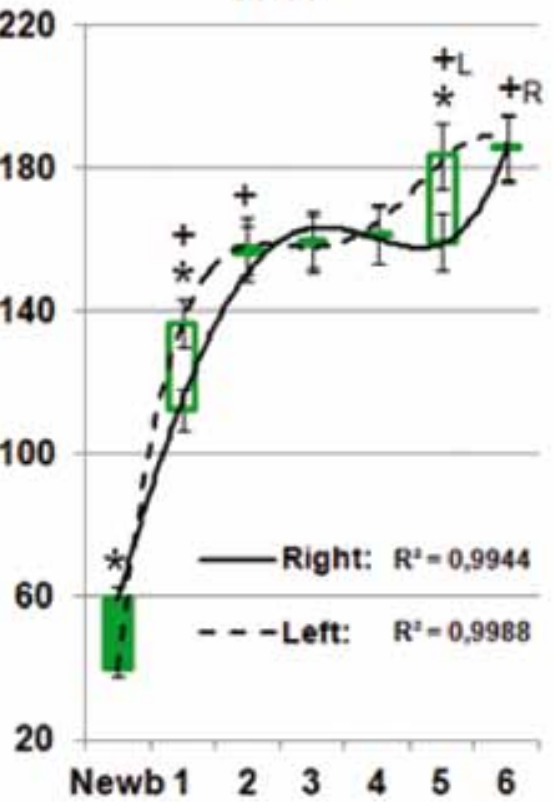

Fig. 2. Changes in the area of piriform neurons in the posterior quadrangular lobule ( $\mathrm{HVI}$ ) of the cerebellum Here and on Fig. 3: $+L$ - significant difference from the previous significant age indicator of the left hemisphere, $+R$ - the same for the right hemisphere.

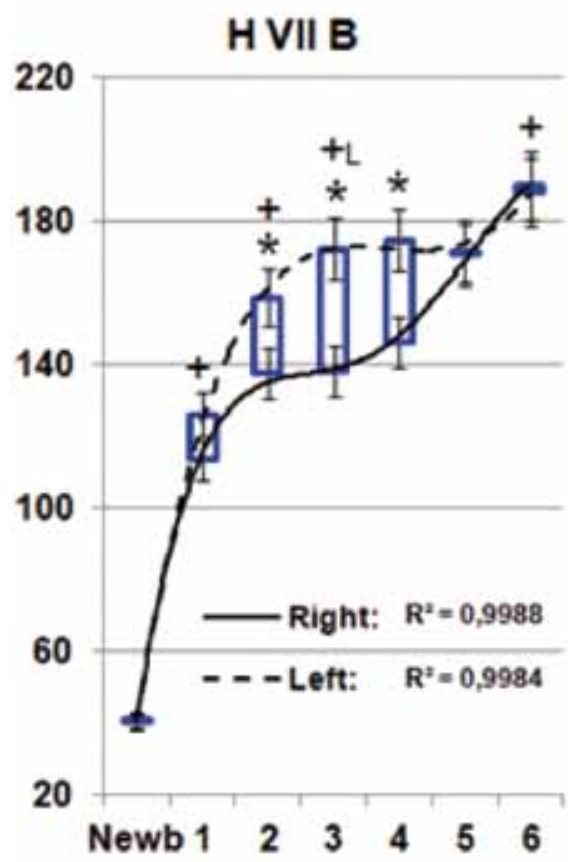

Fig. 3. Changes in the area of piriform neurons in the paramedian lobule (H VII B) of the cerebellum in children from birth to 6 years of age
This publication was prepared with the support of the "Program of the University of People's Friendship University of 5-100" in the framework of the initiative threads № 030210-0-000.

\section{REFERENCES}

1. BELKHIRIA C., MSSEDI E., HABAS C., DRISS

T., DE MARCO G. Collaboration of CerebelloRubral and Cerebello-Striatal Loops in a Motor Preparation Task. Cerebellum. 2018. doi: 10.1007/ s12311-018-0980-z.

2. BOISGONTIER M.P., CHEVAL B., VAN RUITENBEEK P., CUYPERS K., LEUNISSEN I., SUNAERT S., MEESEN R., ADAB H.Z., RENAUD O., SWINNEN S.P. Cerebellar grey matter explains bimanual coordination performance in children and older adults. Neurobiology of Aging. 2018, pp.1-53. doi: 10.1016/j.neurobiolaging.2018.01.016.

3. BOSTAN A.C., DUM R.P., STRICK P.L. Cerebellar networks with the cerebral cortex and basal ganglia. Trends Cogn Sci. 2013. Vol. 17, N 5, pp. 241-254. doi:10.1016/j.tics.2013.03.003.

4. CALIGIORE D., PEZZULO G., BALDASSARRE G., BOSTAN A.C., STRICK P.L., DOYA K., HELMICH R.C., DIRKX M., HOUK J., JÖRNTELL H., LAGO-RODRIGUEZ A., GALEA J.M., 
MIALL R.C., POPA T., KISHORE A., VERSCHURE P.F., ZUCCA R., HERREROS I. Consensus Paper: Towards a Systems-Level View of Cerebellar Function: the Interplay Between Cerebellum, Basal Ganglia, and Cortex. Cerebellum. 2017. Vol. 16, pp. 203-229. DOI 10.1007/s12311-016-0763-3.

5. KOZIOL L.F., BUDDING D., ANDREASEN N., D'ARRIGO S., BULGHERONI S., IMAMIZU H., ITO M., MANTO M., MARVEL C., PARKER K., PEZZULO G., RAMNANI N., RIVA D., SCHMAHMANN J., VANDERVERT L., YAMAZAKI T. Consensus paper: the cerebellum's role in movement and cognition. Cerebellum. 2014. Vol. 13, N 1, pp. 151-177.

6. PALESI F., TOURNIER J.D., CALAMANTE F., MUHLERT N., CASTELLAZZI G., CHARD D., D'ANGELO E., WHEELER-KINGSHOTT C.A.M. Contralateral cerebello-thalamo-cortical pathways with prominent involvement of associative areas in humans in vivo. Brain Struct Funct. 2015. Vol. 220, pp. 3369-3384.

7. PELZER E.A., HINTZEN A., GOLDAU M., VON CRAMON D.Y., TIMMERMANN L., TITTGEMEYER M. Cerebellar networks with basal ganglia: feasibility for tracking cerebello-pallidal and subthalamo-cerebellar projections in the human brain. Eur J Neurosci. 2013. Vol. 38, N 8, pp. 3106-3114. doi: $10.1111 /$ ejn.12314.

8. PEZOULAS V.C., MICHALOPOULOS K., KLADOS M., MICHELOYANNIS S., BOURBAKIS N., ZERVAKIS M. Functional connectivity analysis of cerebellum using spatially constrained spectral clustering. IEEE J Biomed Health Inform. 2018. doi: 10.1109/JBHI.2018.2868918.
9. STEFANOV S.B., KUHARENKO N.S. Uskorennye sposoby kolichestvennogo sravneniya morfologicheskih priznakov i system. [Accelerated methods of quantitative comparison of morphological features and systems]. Blagoveshchensk, VSKHI, 1989.65 p. (In Russ.)

10. STOODLEY C.J., SCHMAHMANN J.D. Functional topography of the human cerebellum. In: M. Manto, T.A.G.M. Huisman (Eds.), Handbook of Clinical Neurology. Vol. 154 (3rd series). The Cerebellum: From Embryology to Diagnostic Investigations. Elsevier; 2018: 59-70. doi:10.1016/b978-0-44463956-1.00004-7.

11. STRICK P.L., DUM R.P., FIEZ J.A. Cerebellum and nonmotor function. Annu Rev Neurosci. 2009. Vol. 32, pp. 413-434. doi:10.1146/annurev. neuro.31.060407.125606.

12. TSEKHMISTRENKO T.A., KLOCHKOVA S.V., MAZLOEV A.B., NIKITYUK D.B., OBUKHOV D.K. Changes in thickness of cortex and its layers in the posterior lobe of the cerebellum in postnatal ontogenesis. Journal of Anatomy and Histopathology. 2018. Vol. 7(4), pp. 88-93 (In Russ.). doi: 10.18499/2225-73572018-7-4-88-93. 